\title{
IDENTIFIKASI DRPS (DRUG RELATED PROBLEMS) PENDERITA ISPA PASIEN PEDIATRIK DI INSTALASI FARMASI RUMAH SAKIT
}

\author{
Musdalipah, Eny Nurhikma \\ Akademi Farmasi Bina Husada Kendari \\ Email : musdalipahapt@gmail.com
}

\begin{abstract}
ABSTRAK
Drug Related Problem (DRP) atau masalah terkait obat adalah bagian dari asuhan kefarmasian (parmaceutical care) yang menggambarkan suatu keadaan, dimana profesional kesehatan (apoteker) menilai adanya ketidaksesuaian pengobatan dalam mencapai terapi yang sesungguhnya. Tujuan penelitian adalah untuk mengidentifikasi DRPs penderita ISPA (Infeksi Saluran Pernafasan Akut) di Instalasi Farmasi Rumah Sakit kota Kendari dengan kategori polifarmasi, interaksi obat dan interval dosis. Penelitian ini menggunakan metode deskriptif dengan pendekatan Cross Sectional, sampel dalam penelitian ini adalah resep pasien pediatrik yang menderita ISPA. Pengambilan sampel menggunakan metode acak sederhana. Data diolah secara deskriptif dan di jabarkan dalam bentuk narasi. Hasil penelitian ini menunjukkan identifikasi DRPs (Drug Related Problems) dari 30 pasien penderita ISPA di temukan $11(36,66 \%)$ pasien $(43,33 \%)$ mengalami DRPs kategori polifarmasi, dan 4 pasien $(13,33 \%)$ mengalami DRPs kategori interval dosis dan tidak di temukan DPRs kategori interaksi obat.
\end{abstract}

Kata Kunci: DRPs, Peresepan, ISPA, Pediatrik

\section{ABSTRACT}

Drug Related Problem (DRP) is a part of pharmaceutical care that describes a situation in which the health professional (pharmacist) assesses a treatment discrepancy in achieving actual therapy. The purpose of this research was identification patient of ISPA (Acute Respiratory Infection) at Pharmacy Installation of Kendari Hospital with Polifarmacy category, drug interaction and dose interval. This research uses descriptive method with Cross Sectional approach, the sample in this research is recipe of pediatric patient suffering from ARI. Sampling using simple random method. Data is processed descriptively and described in the form of narration. The results of this study indicate that based on the identification of DRPS (Drug Related Problems) it can be concluded that from 30 patients with respiratory infection found 11 patients (36.66\%) experienced DRPs polifarmation category, and 4 patients (13.33\%) experienced DRPs category interval Dose and not found DPRs drug interaction category.

Keywords : DRPs, Prescribing, ISPA, Child 


\section{PENDAHULUAN}

Indonesia sebagai daerah tropis yang berpotensi menjadi daerah endemik dari beberapa penyakit infeksi yang setiap saat dapat menjadi ancaman kesehatan bagi kesehatan masyarakat. Pengaruh geografis dapat mendorong terjadinya peningkatan kasus maupun kematian akibat ISPA (Daroham \& Mutiatikum, 2009).

Infeksi Saluran Pernafasan Akut atau yang sering disebut ISPA merupakan penyebab utama morbiditas dan mortalitas penyakit menular di dunia. Setiap tahunnya rata-rata hampir empat juta orang meninggal disebabkan penyakit Infeksi Saluran Pernafasan Akut (ISPA), 98\%-nya disebabkan oleh infeksi saluran pernafasan bawah. Pada bayi, anak-anak, dan orang lanjut usia rata-rata tingkat mortalitasnya cukup tinggi terutama dinegara-negara dengan pendapatan perkapita rendah dan menengah (Depkes RI, 2007).

Menurut WHO tahun 2012, sebesar $78 \%$ balita yang berkunjung ke pelayanan kesehatan adalah akibat ISPA, khususnya pneumonia. ISPA lebih banyak terjadi di negara berkembang dibandingkan negara maju dengan persentase masingmasing sebesar 25\%-30\% dan 10\%$15 \%$. Kematian balita akibat ISPA di Asia Tenggara sebanyak 2.1 juta balita pada tahun 2004 (Fitri, 2012). India, Bangladesh, Indonesia, dan Myanmar merupakan negara dengan kasus kematian balita akibat ISPA terbanyak (Usman, 2012).

Sebagian besar dari infeksi saluran pernapasan hanya bersifat ringan seperti batuk, pilek dan tidak memerlukan pengobatan dengan antibiotik, namun demikian anak akan menderita pneumonia bila infeksi paru ini tidak diobati dengan antibiotik dan dapat mengakibatkan kematian. Pemilihan dan penggunaan terapi antibiotika yang tidak tepat dan rasional akan menentukan keberhasilan pengobatan untuk menghindari terjadinya resistensi bakteri.

Drug Related Problem (DRP) atau masalah terkait obat adalah bagian dari asuhan kefarmasian 
(parmaceutical care) yang menggambarkan suatu keadaan, imana profesional kesehatan (apoteker) menilai adanya ketidaksesuaian pengobatan dalam mencapai terapi yang sesungguhnya. Drug Related Problem (DRP) merupakan permasalahan yang sering terjadi atau muncul dalam pengobatan pasien sehingga terapi yang di dapatkan tidak paripurna atau kejadian-kejadian yang tidak diinginkan terkait dengan penggunaan obat yang baik secara aktual maupun potensial dapat mempengaruhi perkembangan pasien.

Penelitian oIstikomah (2012) dari 100 kasus pasien anak yang memenuhi kriteria inklusi menunjukkan bahwa kejadian DRPs kategori interaksi obat sebanyak 51 kasus $(43,59 \%)$, dosis kurang sebanyak 40 kasus $(34,19 \%)$, dosis lebih sebanyak 9 kasus (22,22\%), dan tidak ditemukannya kategori DRPs obat salah dari total obat yang dianalisis.

Berdasarkan observasi awal di di RSUD kota Kendari ISPA menduduki urutan pertama diantara 10 jenis penyakit dengan jumlah pasien sebanyak 548 jiwa pada periode Januari-Juni 2016 sedangkan periode Januari-Februari 2017 terdapat sebanyak 73 pasien ISPA. Berdasarkan latar belakang di atas, maka penulis tertarik untuk melakukan penelitian tentang bagaimana evaluasi (DRPs) Drug Related Problems penderita ISPA (Infeksi Saluran Pernapasa Akut) pada pasien pediatrik di Instalsi Farmasi Rumah Sakit RSUD Kota Kendari.

\section{METODE PENELITIAN}

\section{Jenis Penelitian}

Jenis penelitian yang digunakan adalah deskriptif yaitu merupakan jenis penelitian yang menggambarkan kejadian atau fakta, keadaan dan variabel dan keadaan yang terjadi saat penelitian berlangsung.

\section{Desain Penelitian}

Pada penelitian ini menggunakan pendekatan Cross Sectional yaitu mempelajari variabel penyebab atau resiko dan akibat terhadap DRP pada Infeksi Saluran 
pernapasan dengan cara

Observasional dan pengumpulan data sekaligus.

\section{Penelitian dilakukan dengan}

cara pengumpulan semua resep pasien ISPA yang datang berobat di Apotek rawat jalan RSUD kota Kendari periode April-Juni 2017, kemudian Resep tersebut di cocokkan, data dibuat dalam bentuk tabel yang mencakup nomor Resep, nama pasien serta DRP penggunaan obat pada pasien ISPA yang terdiri dari poli farmasi, interaksi obat, dan interval dosis kemudian di analisa secara deskriptif kualitatif yaitu menggambarkan dan menjelaskan hasil yang di dapatkan secara rinci lalu di buat kesimpulan.

\section{Populasi dan Sampel Penelitian}

Populasi dalam penelitian ini adalah semua Resep pasien yang datang berobat di RSUD Kota Kendari. Sampel yang digunakan adalah pasien pediatrik penderita ISPA yang datang berobat, dengan kriteria inklusi pasien ISPA yang berumur 0-14 tahun yang mendapatkan terapi antibiotik.

Kriteria insklusi dan eksklusi sebagai berikut:
1. Kriteria inklusi
a. Pasien ISPA yang mendapatkan terapi
b. Pasien ISPA yang berusia 0-14 tahun
c. Mempunyai data resep (nama obat. Dosis obat, dan aturan pakai)

2. Kriteria eksklusi

Pasien yang tidak menderita ISPA.

\section{HASIL DAN PEMBAHASAN}

Infeksi Saluran Pernafasan Akut atau yang sering disebut ISPA merupakan penyebab utama morbiditas dan mortalitas penyakit menular di dunia. Setiap tahunnya rata-rata hampir empat juta orang meninggal disebabkan penyakit Infeksi Saluran Pernafasan Akut (ISPA), 98\%-nya disebabkan oleh infeksi saluran pernafasan bawah.

Masyarakat yang rentan terhadap ISPA adalah balita karena kekebalan tubuhnya masih rendah. Balita dapat mengalami serangan ISPA 5-8 kali setiap tahun terutama mereka yang tinggal di daerah urban. Jumlah penderita ISPA pada balita antara $25-40 \%$ yang dirawat jalan dan 12-35\% dirawat dirmah 
ini dapat terjadi karena pada anak laki-laki sering melakukan aktivitas di luar rumah yang memungkinkan anak laki-laki lebih cenderung mendapatkan resiko lebih besar terpapar bakteri dan terkena penyakit infeksi dibandingkan dengan anak perempuan (Nasronuddin, et al,2007).

\section{Distribusi Penderita ISPA pada}

\section{Anak berdasarkan Usia}

Tabel 2. Distribusi penderita ISPA pada anak berdasarkan usia di RSUD kota Kendari pada periode April-Juni 2017 :

\begin{tabular}{cccc}
\hline No. & $\begin{array}{c}\text { Golongan } \\
\text { Umur }\end{array}$ & $\begin{array}{c}\text { Jumlah } \\
\text { Resep }\end{array}$ & $\begin{array}{c}\text { Persentase } \\
(\%)\end{array}$ \\
\hline 1 & $<1$ & 4 & $13,33 \%$ \\
\hline 2 & $1-10$ & 22 & $73,33 \%$ \\
\hline 3 & $>10$ & 4 & $13,33 \%$ \\
\hline & Total & 30 & $100 \%$ \\
\hline
\end{tabular}

Berdasarkan tabel diatas

Kejadian infeksi paling banyak terjadi pada kelompok usia rentang

\section{Distribusi Jenis Obat yang diberikan}

1-10 tahun yang berjumlah 22 pasien $\quad(45,16 \%)$. Hal ini menunjukkan bahwa usia 1-10 tahun merupakan usia rawan terkena infeksi, karena usia tersebut adalah usia sekolah, dan biasanya anakanak masih menyukai membeli makanan dan minuman di lingkungan sekolah dan di pinggir jalan yang kebersihannya tidak dapat dijamin.

Masalah lain penyebab infeksi pada anak usia 1-10 tahun adalah karena anak usia tersebut lebih aktif bermain atau beraktivitas di luar rumah sehingga anak usia tersebut mudah terpapar asap polusi dan debu. Lingkungan dan pola hidup yang tidak bersih juga dapat menyebabkan tubuh mudah terpapar bakteri (Musnelina et al, 2004).

Tabel 3. Distribusi jenis obat yang diberikan pada pasien penderita ISPA periode AprilJuni 2017

$\begin{array}{ccc}\text { JENIS OBAT } & \text { JUMLAH YG DIGUNAKAN } & \text { PERSENTASE }(\%) \\ \text { Erytromycin } & \frac{\text { ANTIBIOTIK }}{2} & 3,33 \% \\ \text { Amoxicillin } & 15 & 50 \% \\ \text { Cotrimoxasol } & 13 & 43,33 \% \\ \text { Cefadroxyl } & 1 & 3,33 \%\end{array}$


Paracetamol

CTM

Ambroxol

Glyceryl Guaiacolate

Salbutamol

Multi Vitamin

Vitamin C

Vitamin B-Comp
23

\section{ANTIHISTAMIN}

24

\section{EKSPEKTORAN}

3

23

BRONKODILATOR

10

VITAMIN

1

14

2
$33,33 \%$

$76,66 \%$

$80 \%$

$10 \%$

$76,66 \%$

$3,33 \%$

$46,66 \%$

$6,66 \%$
Berdasarkan hasil penelitian yang diperoleh bahwa obat antibiotik yang paling banyak digunakan adalah amoxicillin sebanyak 15 (50\%), amoxicillin menjadi pilihan utama penggunaan antibiotik pada penderita ISPA karena efektivitas dan keamanannya sudah terbukti khususnya pada anak serta harga yang terjangkau (Anonim, 2015). Hal ini diperkuat oleh penelitian Isnawati, dkk (2002), bahwa total resistensi dari amoxicillin ditemukan paling rendah, yakni $1,5 \%$ di bandingkan dengan antibiotik lainnya seperti cotrymoxazole dan erytromycin. Didapatkan penggunaan obat terbesar adalah analgetik-antipiretik yaitu paracetamol sebanyak 23
76,66 \%. Analgetik-antipiretik digunakan untuk pengobatan simptomatik. Paracetamol dapat mengobati panas yang dapat terjadi karena adanya infeksi pada pasien, sehingga tubuh mengalami gangguan metabolisme yang mengakibatkan suhu tubuh me ningkat (Tjay dan Raharja 2007). CTM 24 (80\%) pemberian CTM untuk terapi pendukung ISPA jika pasien mengalami bersin-bersin dan hidung gatal. Glyceryl Guaiacolate 23 (76,66\%) penggunaan Glyceryl Guaiacolate dapat mengencerkan dahak pada gejala batuk pada anak. Vit C $14 \quad(46,66 \%)$ pemberian vitamin pada pasien ISPA yaitu untuk memperkuat sistem imun pada anak yang masih lemah 
terutama pada keadaan sakit anak sangat mudah terserang penyakit lainnya.

\section{DRPs (Drug Related Problems)}

Analisa dari DRPs (Drug

Related Problems) pada pasien ISPA Infeksi Saluran pernafasan Akut di RSUD kota Kendari pada periode bulan April-juni tahun 2017. Ada 3 dari 8 jenis DRPs yang masuk dalam kategori DRPs yaitu poli farmasi, interaksi obat dan interval dosis. Berikut ini adalah tabel mengenai gambaran DRPs pada pasien ISPA RSUD Kota Kendari : Identifikasi DRPs (Drug Related Problems) pada pasien ISPA di gambarkan secara deskriptif dalam bentuk persentase, kejadian DRPs pada pasien ISPA di RSUD kota Kendari dapat dilihat pada tabel berikut :

Tabel 4. Identifikasi DRPs

\begin{tabular}{cccc}
\hline No. & DRPs & Jumlah Kejadian & Persentase (\%) \\
\hline 1. & Poli Farmasi & 13 & $43,33 \%$ \\
\hline 2. & Interaksi obat & 0 & $0 \%$ \\
\hline 3. & Interval dosis & 4 & $3,33 \%$ \\
\hline & Total & 17 & $46,66 \%$ \\
\hline
\end{tabular}




\section{Polifarmasi}

Tabel 6. Polifarmasi terhadap pasien ISPA periode bulan April-Juni 2017 :

\begin{tabular}{|c|c|c|c|c|c|}
\hline No. & Usia (tahun) & Jenis Kelamin & Diagnosa & Terapi obat & Cara penggunaan \\
\hline 1. & $23 \mathrm{bln}$ & Laki-laki & ISPA & $\begin{array}{l}\text { Amoxicillin syr } 3 \mathrm{xl} \\
\text { Pct syr } 3 \mathrm{xl} \\
\text { ctm } 2 \text {, gg } 2 \text {, prednison } 2 \text {, Vit c } 2 \\
\text { mf puly No } 3 \mathrm{xl}\end{array}$ & $\begin{array}{l}3 \mathrm{xl} \\
3 \mathrm{xl} \\
3 \mathrm{xl}\end{array}$ \\
\hline 2 & $14 \mathrm{bln}$ & Perempuan & ISPA & $\begin{array}{l}\text { Cotri moksasol syr lxl } \\
\text { Pct syr } 2 \mathrm{xl} \\
\text { Ctm } 2 \text {, gg } 2 \text {, prednison } 2 \text {, vit c } 2 \\
\text { mf pulv No } 3 \text { xl }\end{array}$ & $\begin{array}{l}1 \mathrm{xl} \\
2 \mathrm{xl} \\
3 \mathrm{xl}\end{array}$ \\
\hline 3. & $7 \mathrm{bln}$ & Laki-laki & ISPA & $\begin{array}{l}\text { Pet } 3 \times 2 / 3 \\
\text { Amoxicillin syr } 3 \times 2 / 3 \\
\text { Ctm } 1 \% \text {, gg } 1 \% \text {, prednison } 1 \% / 2 \\
\text { mf pulv No } 3 \times 1\end{array}$ & $\begin{array}{l}3 \times 2 / 3 \\
3 \times 2 / 3 \\
3 \times 1\end{array}$ \\
\hline 4 & 3 thn & perempuan & ISPA & $\begin{array}{l}\text { cotri moksasol } 2 \mathrm{xl} \\
\text { pet syr } 3 \mathrm{xl} \\
\mathrm{Gg} 3, \mathrm{ctm} 3 \text {, prednison } 3 \\
\text { mf pulv No } 3 \mathrm{xl}\end{array}$ & $\begin{array}{l}2 \mathrm{xl} \\
3 \mathrm{xl} \\
3 \mathrm{xl}\end{array}$ \\
\hline 5. & 8 thun & Laki-laki & ISPA & $\begin{array}{l}\text { amoxicillin } 2503 \mathrm{xl} \\
\text { pet syr } 3 \times 1 / 2 \\
\text { Gg } 5 \text {, prednison } 5 \text {, ctm } 5 \\
\text { mf pulv No } 3 \times 1\end{array}$ & $\begin{array}{l}3 \mathrm{xl} \\
3 \mathrm{xl} 1 / 2 \\
3 \mathrm{xl}\end{array}$ \\
\hline 6. & 8 thn & Laki-laki & ISPA & $\begin{array}{l}\text { cotri moksasol syr } 2 \mathrm{xl} \\
\text { pet syr } 3 \mathrm{xl} 1 / 2 \\
\text { Gg } 5 \text {, prednison } 5 \text {, ctm } 5 \\
\text { mf pulv No } 3 \mathrm{xl}\end{array}$ & $\begin{array}{l}2 \mathrm{xl} \\
3 \mathrm{xl} 1 / 2 \\
3 \mathrm{xl}\end{array}$ \\
\hline 7 & 6 thn & Laki-laki & ISPA & $\begin{array}{l}\text { amoxicillin ayr } 3 \times 1 \\
\text { Gg } 31 / 2, \operatorname{ctm} 31 / 2, \text { prednison } 2 \\
\text { mf pulv No } 3 \text { x } 1\end{array}$ & $\begin{array}{l}3 \times 1 \\
3 \times 1\end{array}$ \\
\hline 8 & $11 \mathrm{bln}$ & Perempuan & ISPA & $\begin{array}{l}\text { amoxicillin syr } 3 \times 1 \\
\text { Pct } 2 \text {, gg } 2, \mathrm{ctm} 2 \text {, prednison } 2 \text {, } \\
\text { vit } c 2 \\
\text { mf pulv No } 3 \times 1\end{array}$ & $\begin{array}{l}3 \times 1 \\
3 x l\end{array}$ \\
\hline 9 & 3 thn & Laki-laki & ISPA & $\begin{array}{l}\text { Pct syr } 3 \mathrm{xl} \\
\text { Amoxicillin } 3 \mathrm{xl} \\
\text { Gg } 2 \text {, ctm } 2 \text {, prednison } 2 \text {, vit } \mathrm{c} 2 \\
\text { mf pulv No } 3 \mathrm{xl}\end{array}$ & $\begin{array}{l}3 \mathrm{xl} \\
3 \mathrm{xl} \\
3 \mathrm{xl}\end{array}$ \\
\hline 10 & 2 thn & Laki-laki & ISPA & $\begin{array}{l}\text { cotri moksasol syr } 2 \mathrm{xl} \\
\text { pet syr } 3 \mathrm{xl} \\
\text { Gg } 3, \mathrm{ctm} 3 \text {, prednison } 3, \mathrm{~B}-\mathrm{com} 3 \\
\text { mf pulv No } 3 \mathrm{xl}\end{array}$ & $\begin{array}{l}2 \mathrm{xl} \\
3 \mathrm{xl} \\
3 \mathrm{xl}\end{array}$ \\
\hline 11 & 2 thn & Perempuan & ISPA & $\begin{array}{l}\text { Pct syr } 3 \mathrm{xl} \\
\text { Amoxicillin } 3 \mathrm{xl} \\
\text { Gg } 2 \text {, ctm } 2 \text {, prednison } 2 \text {, vit } \mathrm{c} 2 \\
\text { mf pulv No } 3 \mathrm{xl}\end{array}$ & $\begin{array}{l}3 \mathrm{xl} \\
3 \mathrm{xl} \\
3 \mathrm{xl}\end{array}$ \\
\hline
\end{tabular}

Dari data pasien dan data obat yang telah didapatkan, diperoleh 30 pasien yang menderita ISPA (Infeksi Saluran Pernafasan). Dan 11 diantaranya mengalami DRPs dengan kategori polifarmasi yaitu 11 pasien anak mendapatkan resep obat puyer dengan 2 macam obat yang berbeda namun mempunyai efek yang sama yaitu CTM dan

Prednison.

Polifarmasi merupakan penggunaan obat dalam jumlah yang banyak dan tidak sesuai dengan kondisi kesehatan pasien. Meskipun istilah polifarmasi telah mengalami perubahan dan digunakan dalam berbagai hal dan berbagai situasi, 
tetapi arti dasar dari polifarmasi itu sendiri adalah obat dalam jumlah yang banyak dalam suatu resep (dan atau tanpa resep) untuk efek klinik yang tidak sesuai. Jumlah yang spesifik dari suatu obat yang diambil tidak selalu menjadi indikasi utama akan adanya polifarmasi akan tetapi juga dihubungkan dengan adanya efek klinis yang sesuai atau tidak sesuai pada pasien (Rambadhe dkk., 2012).

\section{Interaksi obat}

$$
\text { Berdasarkan dari data }
$$
yang di peroleh tidak di temukan resep interaksi obat, dimana sebuah interaksi obat dikatakan terjadi ketika efek dari satu obat diubah dengan adanya obat lain, jamu, makanan, minuman atau beberapa agen kimia lainnya (Stockley 2016).

Interaksi obat terjadi ketika respon pasien terhadap obat diubah oleh obat lain.
Interaksi obat dapat bermanfaat maupun berbahaya bagi tubuh. Interaksi obat yang membahayakan yaitu ketika terjadi peningkatan efek obat yang menyebabkan toksisitas dan penurunan efek obat secara drastis yang mengakibatkan kegagalan terapi (Snyder et all., 2012). 


\section{Interval dosis}

\begin{tabular}{|c|c|c|c|}
\hline Nama Obat & Dosis yang diberikan & $\overline{B B}$ & Dosis Literatur \\
\hline Erhytromucin & $\begin{array}{l}250 \mathrm{mg} \\
3 \times 1\end{array}$ & $15 \mathrm{~kg}$ & $\begin{array}{l}30-50 \mathrm{mg} / \mathrm{kgBB} / \text { hari. dibagi } \\
\text { menjadi jumlah yang sama } \\
\text { tiap } 6 \mathrm{jam}\end{array}$ \\
\hline Amoxicillin & $\begin{array}{l}60 \mathrm{mg} \\
2 \times 1\end{array}$ & $10 \mathrm{~kg}$ & $\begin{array}{l}20-40 \mathrm{mg} / \mathrm{kgBB} / \text { hari tiap } 8 \\
\text { jam }\end{array}$ \\
\hline Cefadroxil & $\begin{array}{l}60 \mathrm{mg} \\
2 \times 1\end{array}$ & $15 \mathrm{~kg}$ & $\begin{array}{l}30 \mathrm{mg} / \mathrm{kgBB} / \mathrm{hari} \text { dibagi } \\
\text { menjadi } 2 \text { dosis. }\end{array}$ \\
\hline Cotrymoxazole & $\begin{array}{l}40 \mathrm{mg} \text { trimethoprim dan } 200 \mathrm{mg} \\
\text { sulfamethoxazole } \\
2 \mathrm{x} \frac{1}{2}\end{array}$ & $15 \mathrm{~kg}$ & $\begin{array}{l}240 \mathrm{mg} / \mathrm{kgBB} \text { /hari di hagi } \\
\text { menjadi } 2 \text { dosis. }\end{array}$ \\
\hline Paracetamol & $\begin{array}{l}60 \mathrm{mg} \\
3 \times 1\end{array}$ & $11 \mathrm{~kg}$ & $\begin{array}{l}20 \mathrm{mg} / \mathrm{kgBB} / \text { hari dalam } \\
\text { dosis terbagi }\end{array}$ \\
\hline Ambroxol & $\begin{array}{l}60 \mathrm{mg} \\
2 \mathrm{x}^{1 / 2}\end{array}$ & $7 \mathrm{~kg}$ & $\begin{array}{l}2,2 \mathrm{mg} / \mathrm{kgBB} / \text { hari dalam } 3 \\
\text { dosis terbagi }\end{array}$ \\
\hline Glyceryl guaiacolate & $\begin{array}{c}100 \mathrm{mg} \\
2 \times 1\end{array}$ & & $\begin{array}{l}\text { <1th tidak } \\
\text { direkomendasikan } \\
\text { 1-2th: } 2 \text { xlmg 2-5th: } 1 \mathrm{mg} \\
\text { setian 4-6jam, max 6mg/hari } \\
\text { 6-12th: } 2 \mathrm{mg} \text { setiap } 4-6 \mathrm{jam}, \\
\text { max } 12 \text { mg hari }\end{array}$ \\
\hline
\end{tabular}

Berdasarkan data pasien dan data resep obat yang telah diperoleh, terdapat 30 pasien yang menderita ISPA (Infeksi Saluran Pernafasan Akut). Dari 30 pasien ISPA tersebut terdapat 4 pasien yg mengalami interval dosis yakni pemberian obat yang tidak sesuai dengan umur dan berat badan pasien. 


\section{KESIMPULAN}

1. Polifarmasi sebanyak 11 pasien $(43,33 \%)$

2. Interval dosis sebanyak 4 pasien $(13,33 \%)$ dan tidak di temukan DPRs kategori interaksi obat.

\section{DAFTAR PUSTAKA}

Cipolle RJ, Strand LM, Morley PC.Pharmaceutical Care Practice. New York: TheMcGraw-Hill Companies, Inc.; 1998.

Daroham, N.E.P. \& Mutiatikum, 2009, Penyakit ISPA Hasil Riset Kesehatan Dasar (Riskerdas) di Indonesia, Puslitbang Biomedis dan Farmasi Jakarta, 50-55

Depkes RI. (2000). Informasi tentang ISPA pada anak balita. Jakarta: pusat penyuluhan kesehatan masyarakat. Di akses pada 20 Januari 2017.

Departemen Kesehatan RI. (2013) : Riskesdas,Jakarta， Departemen Kesehatan RI.

Departenmen Kesehatan RI, (2002). Pedoman pemberantasan penyakit infeksi saluran pernapasan untuk penanggulangan pneumonia pada balita: Jakarta

Kusumawardani, 2010, Identifikasi Drug Realated Problems Kategori Obat salah, Dosis lebih dan Dosi Kurang serta interaksi obat Pada Pasien ISPA Di Instalasi Rawat Inap RSUD Dr. Moewardi Surakarta Tahun 2010, Skripsi Fakultas Farmasi, Universitas Muhammadiyah Surakarta

Lindawaty. (2010). Partikulat (Pm10) Udara Rumah Tinggal Yang Mempengaruhi Kejadian Infeksi Saluran Pernapasan Akut (ISPA) pada balita (Penelitian Dikecamatan Mampang Prapatan Jakarta Selatan Tahun 2009-2010. Tesis, FKM UI

Rambadhe, S, Chakarborty, A, Shrivastava, A, Ptail, UK, Rambadhe, A 2012, 'A Survey on Polypharmacy and Use of Inappropriate Medications.

Prest, M., 2003, Penggunaan Obat Pada Anak, dalam Aslam, M., Tan, C.K., Prayitno, A., Farmasi Klinis : Menuju Pengobatan Rasional dan penghargaan Pilihan Pasien, 191-192, PT. Elex Media Komputindo Kelompok Gramedia, Jakarta.

Worokarti, 2005, Peran Farmasis Dalam Pengelolaan Penderita Penyakit Infeksi Untuk Mencegah Timbulnya Resistensi Antimikroba, Naskah Lengkap Simposium Penyakit Infeksi dan Problema Resistensi 
Antimikroba, 55-69, Surabaya, Amrin Study Group and Infectious Disease Centre dan FKUA RSU Dr, Soetomo

WHO. 2002. Treatment Of Respiratory Track Infections.
Dalam Hajrah. 2013. Ilmu Keperawatan Anak "Kwashiorkor Pada Anak". Program Studi Keperawatan Fakultas Ilmu Kesehatan: UIN ALAUDDIN Makassar. 